\title{
Presynaptic Contributions of Chordin to Hippocampal Plasticity and Spatial Learning
}

\author{
Mu Sun, ${ }^{1,2}$ Mark J. Thomas, ${ }^{3,4}$ Rachel Herder, ${ }^{2}$ M. Lisa Bofenkamp, ${ }^{1,2}$ Scott B. Selleck, ${ }^{2,5}$ and Michael B. 0'Connor ${ }^{1,2}$ \\ ${ }^{1}$ Howard Hughes Medical Institute and Departments of ${ }^{2}$ Genetics, Cell Biology, and Development, ${ }^{3}$ Neuroscience, ${ }^{4}$ Psychology, and ${ }^{5}$ Pediatrics, University \\ of Minnesota, Minneapolis, Minnesota 55455
}

\begin{abstract}
Recently, several evolutionary conserved signaling pathways that play prominent roles in regulating early neurodevelopment have been found to regulate synaptic remodeling in the adult. To test whether adult neuronal expression of bone morphogenic protein (BMP) signaling components also plays a postnatal role in regulating neuronal plasticity, we modulated BMP signaling in mice both in vivo and in vitro by genetic removal of the BMP inhibitor chordin or by perfusing recombinant BMP signaling pathway components onto acute hippocampal slices. Chordin null mice exhibited a significant increase in presynaptic transmitter release from hippocampal neurons, resulting in enhanced paired-pulse facilitation and long-term potentiation. These mice also showed a decreased acquisition time in a water maze test along with less exploratory activity during Y-maze and open-field tests. Perfusion of BMP ligands onto hippocampal slices replicated the presynaptic phenotype of chordin null slices, but bath application of Noggin, another antagonist of BMP signaling pathway, significantly decrease the frequency of miniature EPSCs. These results demonstrate that the BMP signaling pathway contributes to synaptic plasticity and learning likely through a presynaptic mechanism.
\end{abstract}

Key words: BMP; chordin; hippocampus; synaptic plasticity; learning and memory; neurotransmission

\section{Introduction}

Many components of the bone morphogenic protein (BMP) signaling pathway, a distinct subfamily within the TGF- $\beta$ s, are expressed in different parts of the mammalian adult brain, including the hippocampus (Soderstrom et al., 1996; Pappano et al., 1998; Scott et al., 2000). Despite this strong expression in the adult brain, their potential role in regulating postnatal neuronal plasticity in vertebrates has not been investigated. All members of the TGF- $\beta$ superfamily bind to and activate transmembrane serine/threonine receptors, which, during canonical signaling, transduce transcriptional regulatory signals to the nucleus via phosphorylation and nuclear import of Smad (Sma and Madrelated protein) transcription factors (Shi and Massague, 2003). Noncanonical pathways that signal through mitogen-activated protein kinase (MAPK), LIM (Lin-11/Isl-1/Mec-3 gene products) kinase, PKC $\alpha$, and small GTPases have also been identified (Derynck and Zhang, 2003; Moustakas and Heldin, 2005).

BMP signals regulate numerous developmental, physiological, and homeostatic processes, including, but not limited to, early embryonic patterning, organ development, apoptotic responses, and bone remodeling (Shi and Massague, 2003). From a neurodevelopment point of view, BMPs are critical for neural

Received April 10, 2007; revised June 2, 2007; accepted June 6, 2007.

M.B.0. is an investigator of Howard Hughes Medical Institute. We are grateful to Drs. Anna Petryk and Lorene M. Lanier for advice on mouse genetics and hippocampal neuronal culture. We thank Dr. Bob Hafner and Alice Ressler of the EM Characterization Facility at University of Minnesota for technical help in preparing and analyzing EM sections. We thank Dr. John Klingensmith for supplying us with the chordin knock-out mice.

Correspondence should be addressed to Michael B. O'Connor, Department of Genetics, Cell Biology, and Development, 6-160 Jackson Hall, University of Minnesota, Minneapolis, MN 55455. E-mail: moconnor@mail.med.umn.edu. DOl:10.1523/JNEUROSCI.1604-07.2007

Copyright $\odot 2007$ Society for Neuroscience $\quad$ 0270-6474/07/277740-11\$15.00/0 induction (Sasai, 2001; Rhinn et al., 2006) and neuronal lineage determination (Mehler et al., 1997). In addition to these neurodevelopment roles, BMPs have also been found recently to regulate synaptic homeostasis at the Drosophila neuromuscular junction (NMJ) by a retrograde mechanism (Aberle et al., 2002; Marques et al., 2002; McCabe et al., 2003; Rawson et al., 2003). BMP signals also regulate synaptic transmission between motor neurons and interneurons in the CNS of Drosophila, suggesting that BMP signaling likely integrates the development and function of the central motor circuitry to help coordinate larval movements (Baines, 2004).

The importance of BMP signaling in regulating synaptic function in Drosophila, coupled with the high level expression of BMP signaling components in the mammalian hippocampus, prompted us to examine whether modulation of BMP signaling alters hippocampal function. According to the Allen Brain Atlas, there are numerous BMPs expressed in hippocampus, including BMP2, BMP4-BMP7, and BMP10. Because elimination of most BMP signaling components results in early embryonic lethality (Zhao, 2003), we chose to examine whether loss of chordin alters hippocampal physiology, learning, memory, or other behavior. Chordin is a secreted extracellular antagonist of BMP signaling whose only known function is to bind BMP ligands and prevent them from interacting with their receptors (Piccolo et al., 1996). Chordin is expressed in many tissues throughout development, including the hippocampus (Pappano et al., 1998; Scott et al., 2000). We find that loss of chordin results in a presynaptic transmitter release defect that enhances short- and long-term synaptic plasticity in slice preparations. In addition, these mice exhibit altered cognitive behaviors in Y-maze and open-field tests as well as a significantly enhanced learning rate in Morris water maze 
tests. Because acute application of BMP6, but not BMP2, to hippocampal slices could also increase transmitter release probability and paired-pulse facilitation (PPF) similar to that seen in chordin knock-out mice, we suggest that BMP signaling can regulate synaptic plasticity and learning behavior through a presynaptic mechanism.

\section{Materials and Methods}

Animals. Two- to 3-month-old chordin $\mathrm{Chrd}^{-/-}$and $\mathrm{Chrd}^{+/+}$male mice (Bachiller et al., 2000) were used in this study following protocols approved by the Research Animal Resources committee at the University of Minnesota.

Preparation of hippocampal slices. Mice were decapitated after anesthesia, and hippocampal slices ( $350 \mu \mathrm{m}$ thick) were cut in ice-cold artificial CSF (ACSF) containing the following (in mM): 250 sucrose, $25 \mathrm{NaHCO}_{3}$, 25 glucose, $2.5 \mathrm{KCl}, 1.25 \mathrm{NaH}_{2} \mathrm{PO}_{4}, 2 \mathrm{CaCl}_{2}$, and $1.5 \mathrm{MgCl}_{2}$, pH $7.3(320$ $\mathrm{mOsm})$. The slices were recovered in a submerged chamber at room temperature $\left(24-25^{\circ} \mathrm{C}\right)$ in carbogen-bubbled ACSF, containing $125 \mathrm{~mm}$ $\mathrm{NaCl}$ in place of $250 \mathrm{~mm}$ sucrose, for at least $2 \mathrm{~h}$ before the start of recordings.

Extracellular field EPSP recordings, PPF, and long-term potentiation (field). Recordings were made in a standard interface chamber or submerged chamber and held at $30^{\circ} \mathrm{C}$ [Fine Science Tools (Foster City, CA) and Warner Instruments (Hamden, CT)] with $1-2 \mathrm{ml} / \mathrm{min}$ perfusion speed. A test pulse is given by a custom-designed platinum bipolar electrode (MX21CEPMS1; FHC, Bowdoinham, ME) for stimulating Schaffer collaterals at $0.05 \mathrm{~ms}$ duration and every $20 \mathrm{~s}$. Field EPSP (fEPSP) was recorded by $1-2 \mathrm{M} \Omega$ glass recording in the stratum radiatum of CA1 in the hippocampal slice. Data were acquired through Axoclamp B and pClamp 8 software (Molecular Devices, Palo Alto, CA).

PPF was examined at 25, 50, 100, and $200 \mathrm{~ms}$ interstimulus intervals (ISIs) with stimulation strength correlated to $30 \%$ of the maximal fEPSP. Stimuli intensity correlated to $50 \%$ maximal fEPSP slope was used for baseline and induction of LTP. Induction protocol is single train, $100 \mathrm{~Hz}$, $1 \mathrm{~s}$ or theta burst stimulation (TBS) that entailed four trains of 10 bursts of four stimuli with $20 \mathrm{~s}, 200 \mathrm{~ms}$, and $10 \mathrm{~ms}$ intervals between trains, burst, and stimuli, respectively (Law et al., 2003). For late-phase longterm potentiation (LTP), 30\% maximal fEPSP was set as basal synaptic transmission and four trains of $100 \mathrm{~Hz}$ for $1 \mathrm{~s}$ duration with $5 \mathrm{~min}$ interval induced at least $3 \mathrm{~h} \mathrm{LTP.} \mathrm{To} \mathrm{analyze} \mathrm{the} \mathrm{depolarization} \mathrm{envelope}$ during induction of LTP, the negative area of each depolarization trace was normalized by correlated baseline slope of fEPSP.

Whole-cell patch-clamp, miniature EPSC recordings and pairing protocol induced LTP. Pyramidal neurons in CA1 were identified by infrared differential interference contrast microscope under a submerged recording chamber; data were acquired by Multipatch (Molecular Devices) and customized Igor software (WaveMetrics, Lake Oswego, OR). Patch electrodes (3-5 M $\Omega$ ) contained the following (in mM): 117 cesium gluconate or potassium gluconate, $2.8 \mathrm{NaCl}, 20$ HEPES, 0.4 EGTA, 5 tetraethylammonium-Cl, 2.5 MgATP, and 0.25 MgGTP, pH 7.2-7.4 (285-295 mOsm). Miniature EPSCs (mEPSCs) of pyramidal neurons were recorded voltage clamped at $-60 \mathrm{mV}$ with $1 \mu \mathrm{M}$ TTX and $20 \mu \mathrm{M}$ bicuculline. Human recombinant BMP6, BMP2, and Noggin (R\&D Systems, Minneapolis, MN) were perfused at $200 \mathrm{ng} / \mathrm{ml}$ concentration and at a flow rate of $2 \mathrm{ml} / \mathrm{min}$ for $5 \mathrm{~min}$. mEPSCs were detected by Mini Analysis Program (Synaptosoft, Decatur, GA) from continuous recordings of every $3 \mathrm{~min}$.

Evoked EPSCs were recorded by patch pipettes (3-5 M $\Omega$ ) filled with the intracellular solution containing the following (in $\mathrm{mM}$ ): $5 \mathrm{KCl}, 135$ K-gluconate, 10 HEPES, 0.2 EGTA, 2.5 Mg-ATP, 0.25 Na-GTP, 10 glucose, and 5 QX-314 [ $N$-(2,6-dimethylphenylcarbamoyl methyl)triethylammonium chloride], pH 7.2-7.25 (290-300 mOsm). Cells were held at $-60 \mathrm{mV}$. LTP was induced by pairing of stimulation of Schaffer collaterals at $1 \mathrm{~Hz}$ for $100 \mathrm{~ms}$ by glass stimulating electrode with depolarization of the postsynaptic cell to $0 \mathrm{mV}$. Care was taken to avoid "washout" of LTP, by inducing LTP within 15 min after disruption of the cell plasma membrane. Serial resistance in whole-cell configuration was $\sim 25-40$ $\mathrm{M} \Omega$. Cells were discarded when either input or serial resistance changed
$>25 \%$ after baseline recording. Resting potentials normally were from -60 to $-65 \mathrm{mV}$.

Immunocytochemistry and staining. Twenty micrometer cryosections from adult mice were incubated with primary antibodies at $1: 200,4^{\circ} \mathrm{C}$ overnight. After incubation with fluorescently labeled secondary antibodies for $1 \mathrm{~h}$ at room temperature, $Z$-stack images were captured and processed using a Zeiss (Oberkochen, Germany) Axioplan 2 microscope equipped with a Carve spinning disk (Atto Instruments, Rockville, MD) and Axiovision software (Zeiss). Anti-phosphorylated Smad (pSmad) antibodies were either purchased from Upstate Biotechnology (Lake Placid, NY) and Cell Signaling Technology (Beverly, MA) or were a gift from Dr. Carl-Henrick Heldin (Ludwig Center for Cancer Research, Uppsala, Sweden). Anti-chordin and BMP receptor type II (BMPRII) antibodies were purchased from R\&D Systems. Anti-microtubuleassociated protein 2 (Map2) and synapsin I were obtained from Chemicon (Temecula, CA).

Hippocampal and glial cultures were prepared from embryonic day 16 and postnatal 0 mice, respectively, following a published protocol (Strasser et al., 2004). Approximately $1 \times 10^{4}$ hippocampal cells were plated on each $12 \mathrm{~mm}$ coverslip inside $35 \mathrm{~mm}$ culture dishes. On day 4, 3 $\mu \mathrm{M} \mathrm{AraC}$ was put into the culture to maintain pure primary neuronal culture. Staining of BMPRII (1:10; R\&D Systems), synapsin I (1:100; Chemicon), and Map2 (1:200; Chemicon) was performed on 1-week-old hippocampal cultured neuron.

Mouse brains were impregnated following the user manual of FD Rapid GolgiStain kit (FD NeuroTechnologies, Ellicott City, MD), 100 $\mu \mathrm{m}$ cryosections were stained and observed under $100 \times$ objective. The tertiary dendrites ( $>10 \mu \mathrm{m}$ segment) in stratum radiatum were traced, and a serial set of pictures, which cover all spines on the dendrite, were taken and $Z$-projected by maximal intensity using NIH ImageJ software.

Electron microscopy. The fixative containing $2 \%$ formaldehyde, $2.5 \%$ glutaraldehyde, and $2 \mathrm{~mm} \mathrm{CaCl}_{2}$ in $0.1 \mathrm{M}$ cacodylate buffer was perfused transcardially. The mouse brains were intact inside the skull for $1 \mathrm{~h}$, and then coronal $400 \mu \mathrm{m}$ hippocampal slices were cut by a Vibroslicer (World Precision Instruments, Sarasota, FL) inside a chamber filled with $0.1 \mathrm{M}$ cacodylate buffer. Slices were soaked in $1 \% \mathrm{OsO}_{4}$ with $1.5 \%$ potassium ferrocyanide and for an additional $1 \mathrm{~h}$ in $1 \% \mathrm{OsO}_{4}$. Next, slices were treated following standard procedures (Harris and Sultan, 1995) and thin sectioned at $50 \mathrm{~nm}$. Regions $200 \mu \mathrm{m}$ distant from the pyramidal CA1 soma in the striatum radiatum were observed at 50,000 $\times$ magnification with Jeol (Peabody, MA) 1200EX Transmission Electron Microscopy. Only synapses with clear presynaptic and complete postsynaptic structure were selected for counting and measuring by a second researcher who did not know the identity of the samples. Docked vesicles are defined as vesicles $<100 \mathrm{~nm}$ from the presynaptic membrane. Active zone length was measured from the width of postsynaptic density as two aligned oppositely each other.

Behavioral assays. Animal behaviors were video taped and analyzed by both real-time and off-line versions of Topscan system (Clever Systems, Reston, VA).

$Y$-maze. The Y-maze includes three identical arms $(36 \mathrm{~cm}$ long $\times 12.5$ $\mathrm{cm}$ high $\times 7.5 \mathrm{~cm}$ wide, made of transparent Plexiglas) and a $7.5 \mathrm{~cm}$ hexagon as the hub in the center of the maze. Around the Y-maze, visual cues enable the animal to locate itself spatially. During the acquisition trial, one arm is blocked. A mouse is placed into the hub and allowed to freely explore the two open arms and the hub for $15 \mathrm{~min}$. After an intertrial interval of $3 \mathrm{~h}$, the mouse is placed in the maze with all arms open for 5 min (recall trial). The number of entries made into each arm is recorded. (Dellu et al., 1992).

Open field. An individual mouse was put into each of four test cages $(50 \times 50 \times 40 \mathrm{~cm})$ with a novel object $(5$-cm-diameter bottle cap) 12.5 $\mathrm{cm}$ from the wall. Mice were allowed to explore the cages for $15 \mathrm{~min}$, and their movements were recorded.

Morris water maze (Morris, 1984) analysis was performed in a 1.2-mdiameter opaque pool in which a nontoxic tempera white paint was added. Water depth was $50 \mathrm{~cm}$, and the surface was $20 \mathrm{~cm}$ from the ridge of the pool. Water temperature was monitored and kept at $24 \pm 0.5^{\circ} \mathrm{C}$ throughout the training. Mice were trained to locate a submerged $10 \mathrm{~cm}$ platform $(0.5 \mathrm{~cm}$ under the water $)$ in an arbitrary quadrant of the pool 
during $90 \mathrm{~s}$ training trials. Posters on the wall and other fixtures in the testing room served as spatial cues. Mice were allowed to stay on the platform for $15 \mathrm{~s}$ before they were dried and returned to their home cages. Two trials per day with a $30 \mathrm{~min}$ interval between trials were given at the same time of each training day. On the first day of the experiment (day 0), an individual mouse was put on the platform with a visible cue ( $15 \mathrm{~cm}$ flag) for $15 \mathrm{~s}$ as a primer. Mice were then placed tail-end low, facing the wall, at any one of five randomly selected points in one of three other quadrants, with approximately equal distance to the platform. During the probe trial, mice swam $60 \mathrm{~s}$ without a platform, and the length of stay in each quarter was analyzed. After the first probe test, the platform was put in a new position, then mice were trained another $6 \mathrm{~d}$ (reversal test), and then a second probe test was performed on day 18 .

\section{Results}

Expression of BMP signaling pathway components in the adult mouse hippocampus

A number of previous reports have shown expression of several BMP signaling pathway members in the adult hippocampus (Soderstrom et al., 1996; Pappano et al., 1998; Scott et al., 2000), but it is not clear whether this pathway is actually active in mature neurons because some important signaling pathway components that play a role in directing neurodevelopment are shut off after maturation of the CNS. Previous in situ hybridization results showed that the BMPRII receptor is expressed in the hippocampus. We examined the distribution of the BMPRII receptor protein and found that is expressed in all regions of the hippocampus (CA1-CA3 and the dentate gyrus). To examine the subcellular localization of the BMPRII receptor in synaptic structures, we double stained cultured hippocampal pyramidal neurons isolated from 1-week-old mice with antibodies against the presynaptic marker synapsin I and BMPRII. We found that BMPRII is localized to both dendrites and axons. However, in culture, we see a strong colocalization of synapsin I puncta (a presynaptic marker) with BMPRII patches, suggesting that BMP signaling can potentially modulate presynaptic function (Fig. $1 E, F)$

To determine whether mature hippocampal cells actually receive BMP signals, we stained adult hippocampal (8 weeks old) (Fig. 1A) slices with three different anti-pSmad1/5 antibodies. All three gave similar patterns of immunoreactivity within the hippocampus and stained pyramidal neurons, interneurons, and astrocytes in the CA1-CA3 regions as well as the dentate gyrus (Fig. 1B). These observa-
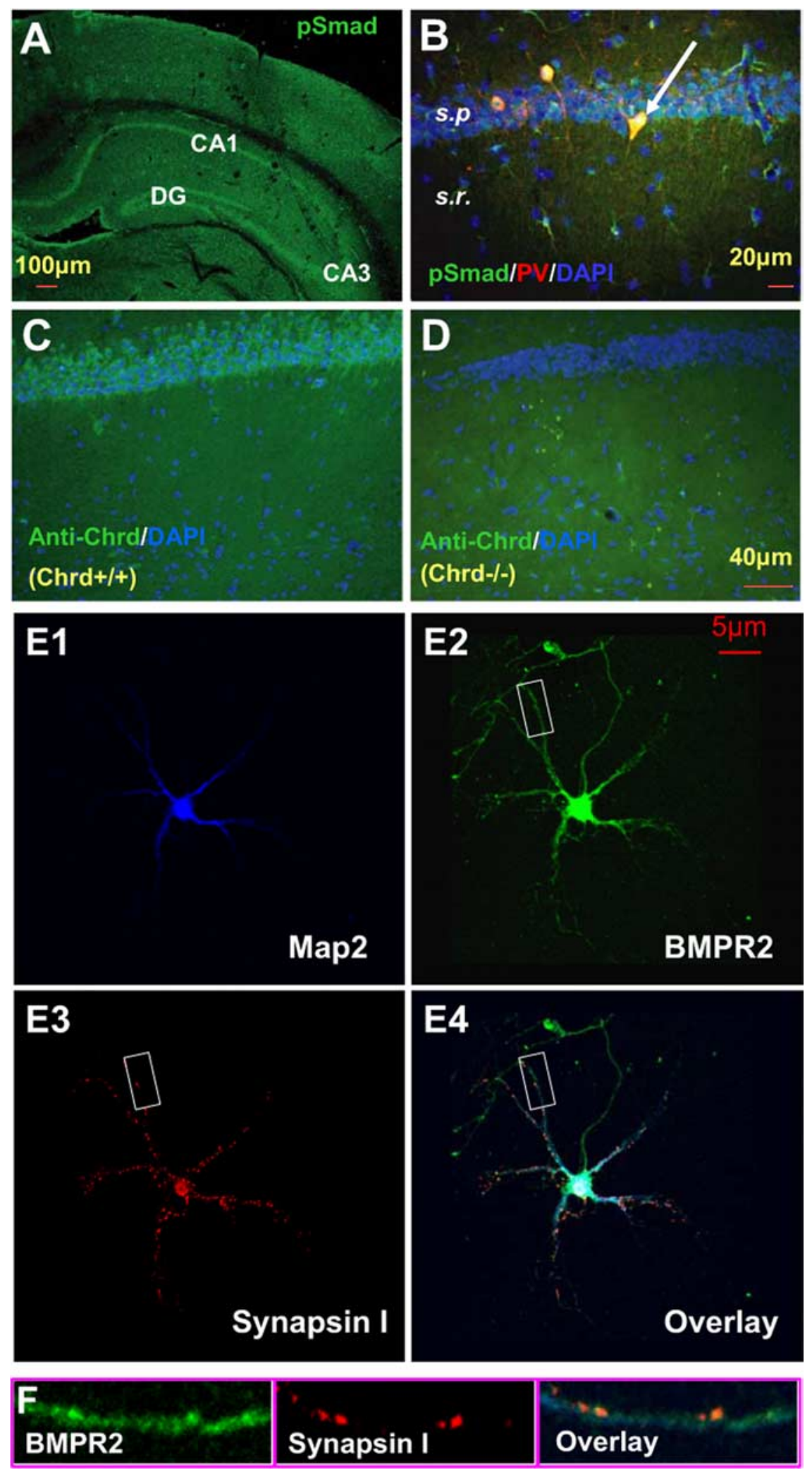

Figure 1. $\quad A$, Expression pattern of BMP signaling pathway components in the mouse hippocampus. Anti-pSmad staining in adult wild-type mouse hippocampus; cell body layers showed strong staining, including CA1, CA3, and dentate gyrus (DG) regions. $B$, AntipSmad staining under higher magnification; signals are seen in pyramidal neurons of $C A 1$, inhibitory neurons (parvalbumin positive), and astrocytes (typical morphology). Blue channel shows $4^{\prime}, 6^{\prime}$-diamidino-2-phenylindole (DAPI) nuclear counterstaining. Note that not all cell bodies show pSmad accumulation. Striatum pyramidal (s.p.) and striatum radiatum (s.r.) are labeled. C, D, Anti-Chrd staining in CA1 of Chrd ${ }^{+/+}$and $\mathrm{Chrd}^{-/-}$slices. Note the strong Chrd signal in the wild-type pyramidal cells (C) but not in the mutant (D). E1-E4, BMPRII can be detected on 1-week-old hippocampal pyramidal neuronal cultured cells. E1, Map2 staining of dendrites. E2, E3, BMPRII staining in dendrites (E2) and the axon synapsin l-stained synaptic structure (E3).E4, Overlay of $\boldsymbol{E 1 - E 3 . F}$, Higher magnification showed colocalization of synapsin I and BMPRII at synaptic structures. 

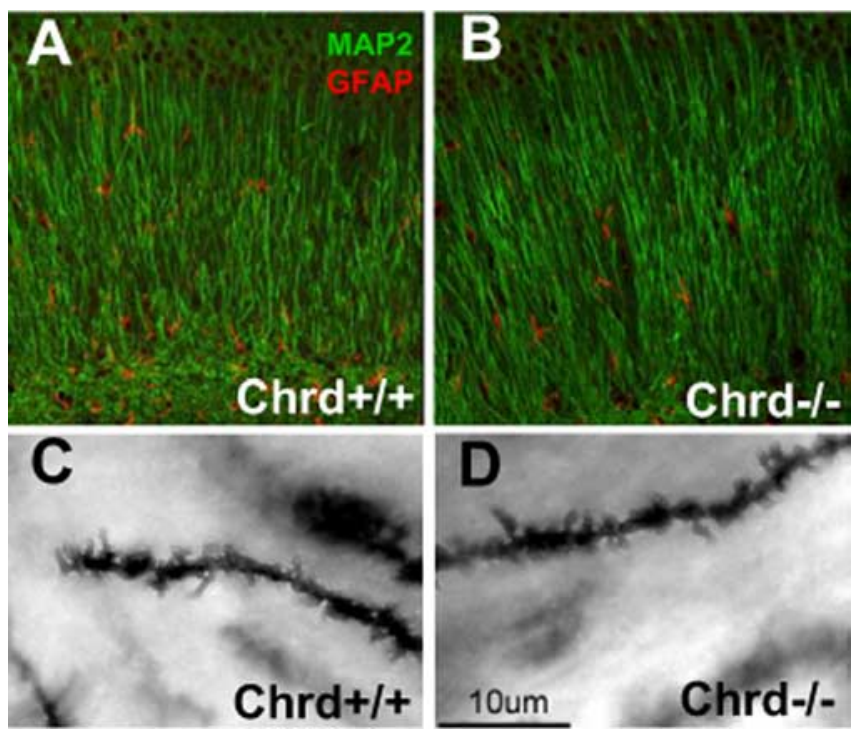

Figure 2. Normal dendritic architecture and spine density is seen in the hippocampus of $\mathrm{Chrd}^{-/-}$mice. $\boldsymbol{A}, \boldsymbol{B}, \mathrm{Map} 2$ and GFAP double staining of the CA1 region from $\mathrm{Chrd}^{+/+}(\boldsymbol{A})$ and $\mathrm{Chrd}^{-/-}(\boldsymbol{B})$ mice. Map2 staining (green) showed a similar dendrite branching pattern from both genotypes; GFAP staining (red) showed a similar distribution and density of astrocytes both genotypes. $C, D$, Golgi staining showing apical tertiary dendrites of CA1 pyramidal neurons from $\mathrm{Chrd}^{+/+}$and $\mathrm{Chrd}^{-1-}$, respectively.

tions suggest that, like recent observations at the NMJ in Drosophila (Dudu et al., 2006), in the 8-week-old hippocampus, both presynaptic and postsynaptic cells are receiving BMP signals.

We next examined whether the BMP inhibitor chordin is also present in hippocampal tissue. Like BMPRII and pSmad, we observed strong signals from all hippocampal regions, including CA1-CA3 and the dentate gyrus. This staining is specific for chordin because slices from $\mathrm{Chrd}^{-1-}$ mouse brains showed no staining (Fig. 1C,D). Because loss of chordin might be expected to increase the level of BMP signaling, we also stained chordin mutant brains with anti-pSmad antibodies. Surprisingly, we could detect no obvious differences in staining levels either by immunolocalization or on Western blots of isolated hippocampal tissue (data not shown), although small changes $(<2 \times)$ or changes in only a small subset of cells might have been missed. The lack of an effect of chordin loss on steady-state levels of pMad phosphorylation, however, does not rule out that chordin loss may result in alterations in BMP signaling through non-Smad-dependent mechanisms (see Discussion).

\section{$\mathrm{Chrd}^{-/-}$mice show normal hippocampal morphology and} dendritic structure

Although $50 \%$ of $\mathrm{Chrd}^{-/-}$mice died perinatally in C57BL/6 background, those that survive exhibit a normal gross morphology of the CNS (Bachiller et al., 2003). We found that hematoxylin and eosin staining of $\mathrm{Chrd}^{-/-}$brain sections also showed normal gross anatomy of hippocampal structures (data not shown). Because it has been found that BMPs can stimulate dendrite growth of cultured neurons (Lein et al., 1995; Withers et al., 2000), we wanted to determine whether loss of chordin changed dendritogenesis in the hippocampus. Using anti-Map2 staining as a marker for dendrite structure, we observed no differences in dendritic morphology in the striatum radiatum of $\mathrm{Chrd}^{-/-} \mathrm{mu}-$ tant mice compared with wild type (Fig. $2 A, B$ ). We also examined the density of astrocytes inside hippocampus, because overexpression of BMP4 has been shown to result in an expansion of the astrocyte population (Gomes et al., 2003). Using an antiGFAP antibody to mark astrocytes, we observed no significant difference in the pattern or density of GFAP-positive glial cells inside hippocampus of $\mathrm{Chrd}^{-/-}$animals compared with wild type (Fig. $2 A, B$ ).

Last, we wanted to examine dendritic spine morphology and density because alterations in either of these might significantly change the electrophysiological properties of hippocampal neural circuits. To test whether loss of chordin altered the spine density of hippocampal tertiary dendrites, Golgi-impregnated brains from mutant and littermate control mice were sectioned, and spine numbers were counted (double-blind study). We found no significant difference in average spine density between $\mathrm{Chrd}^{-/-}$and wild-type mice in CA1 $\left(\mathrm{Chrd}^{-/-}, 12.9 \pm 0.6 / 10\right.$ $\left.\mu \mathrm{m} ; \mathrm{Chrd}^{+/+}, 12.1 \pm 0.6 / 10 \mu \mathrm{m} ; \mathrm{p}=0.38\right)$. In summary, our morphological assays reveal that removal of chordin has no significant effect on the general development of the hippocampus, including gross structure, glial proliferation, dendritogenesis, and spinogenesis.

\section{$\mathrm{Chrd}^{-1-}$ mutant mice exhibit increased paired-pulse facilitation and transmitter release}

Because BMP signaling has been shown to strongly regulate glutamatergic transmission at the Drosophila NMJ (Aberle et al., 2002; Marques et al., 2002; McCabe et al., 2003) and because BMPs have been shown to potentiate glutamate-mediated currents in human retina neurons (Shen et al., 2004), we analyzed basic synaptic transmission inside CA1 region of hippocampus, in which the synapses are formed by axon terminals from the Schaffer collaterals of CA3 neurons onto apical dendrites of CA1 pyramidal neurons. The stimulus-response curves from $\mathrm{Chrd}^{-/-}$ mutant animals and control slices overlay very well, indicating that there is no general alteration in excitatory synaptic transmission in chordin mutants (Fig. 3A).

We next used a paired-pulse facilitation protocol to examine short-term plasticity in chordin mutants. $\mathrm{Chrd}^{-1-}$ slices show a strikingly enhanced PPF compared with littermate controls when the interpulse interval was $<100 \mathrm{~ms}$ (Fig. $3 B$ ). We next studied mEPSCs by the whole-cell patch-clamp technique to differentiate between presynaptic or postsynaptic involvement effects in $\mathrm{Chrd}^{-/-}$animals. The amplitude of mEPSCs from $\mathrm{Chrd}^{-/-} \mathrm{CA1}$ pyramidal neurons was normal compared with wild-type controls (Fig. 3C). However, the frequency of mEPSCs in $\mathrm{Chrd}^{-/-}$ animals increased significantly $(0.45 \pm 0.03$ vs $0.77 \pm 0.08 \mathrm{~Hz}$; $p=0.003$ ) (Fig. 3C) compared with control animals. The higher $\mathrm{PPF}$ and mini frequency from $\mathrm{Chrd}^{-/-}$animals suggests that chordin is acting presynaptically to control transmitter release. This finding is consistent with the Drosophila data in which presynaptic loss of BMP signaling results in a decrease in mEPSC frequency and no change in amplitude (Marques et al., 2002). In chordin mutants, which presumably have an increased level of BMP signaling, we see an increase of mEPSC frequency and no change in amplitude.

\section{$\mathrm{Chrd}^{-/-}$hippocampal synapses exhibit morphological} alterations at the ultrastructural level

Because $\mathrm{Chrd}^{-1-}$ mutants show altered transmitter release and short-term plasticity, we wanted to determine whether an ultrastructural change in synapse morphology might underlie these defects. To explore this issue, we examined the ultrastructure of hippocampal synapses from $\mathrm{Chrd}^{-/-}$mice and littermate controls using transmission electron microscopy (Fig. 4A,B). In a double-blind study, we found that $\mathrm{Chrd}^{-/-}$axon terminals 


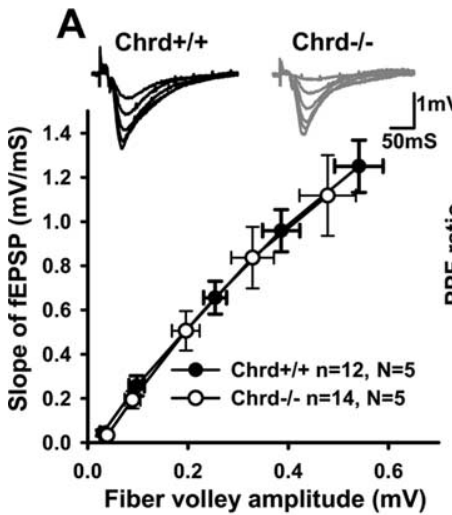

B
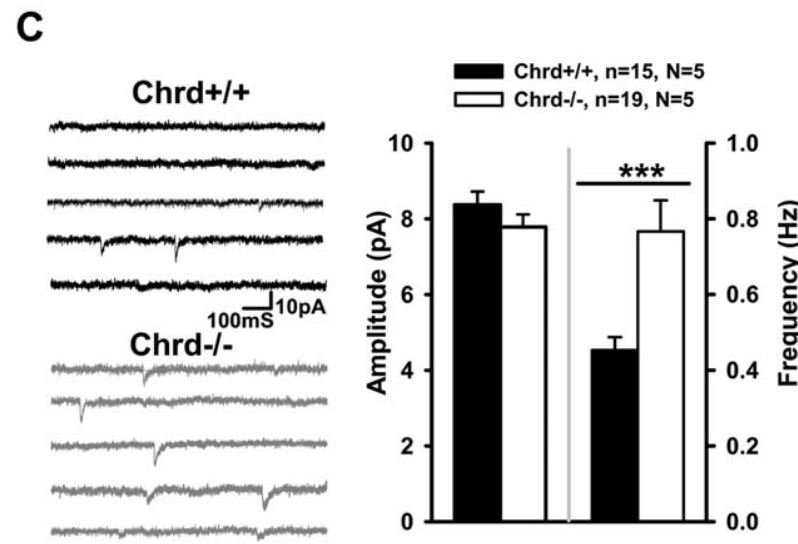

Figure 3. Increased PPF and mEPSC frequency in $\mathrm{Chrd}^{-/-}$slices. A, Relationship between the slope of fEPSP and amplitude of presynaptic fiber volley for $\mathrm{Chrd}^{-/-}$and $\mathrm{Chrd}^{+/+}$mice. Data are expressed as mean \pm SEM. Representative traces of fEPSPs evoked with different stimulus strengths are shown in the insets. $B$, PPF was measured as the ratio between the slopes of fEPSPs evoked by the second and first pulses and plotted for several ISIs. Field EPSPS were evoked with a stimulus that evoked $30 \%$ of the maximal fEPSP. Values represent mean \pm SEM; ${ }^{*} p<0.05,{ }^{* *} p<0.01$ (unpaired $t$ test). Representative traces of fEPSPs evoked with $25 \mathrm{mSISI}$ are shown in the insets. C, Increase in the frequency of mEPSCs in $\mathrm{Chrd}^{-1-}$ mice. Examples of mEPSCs recorded in $\mathrm{Chrd}^{-/-}$and $\mathrm{Chrd}^{+/+}$mice are shown in the left. Note the significant difference in the mean frequency of mEPSCs recorded in slices from $\mathrm{Chrd}^{-/-}$and $\mathrm{Chrd}^{+/+}$ mice ${ }^{* * *} p<0.005$, unpaired test). Data are presented as mean \pm SEM. There is no significant difference for $\mathrm{mEPSC}$ amplitude between genotypes.

showed a significantly higher number of docked vesicles per active zone length (Table 1), consistent with the higher release probabilities (mEPSCs) from $\mathrm{Chrd}^{-1-}$ boutons. We also found that the width of synaptic cleft from $\mathrm{Chrd}^{-1-}$ synapses was slightly but significantly decreased, which might contribute to changes in synaptic efficacy.

\section{Application of BMP6 but not BMP2 mimics the effects of chordin loss on mEPSCs and PPF}

To examine directly whether enhanced BMP signaling produces the same changes in presynaptic release properties as those seen in $\mathrm{Chrd}^{-/-}$animals, we perfused two different BMP ligands onto C57BL/6 slices and measured mEPSC frequency and PPF. We found that, when perfused with BMP6 (2 ml/min, of $200 \mathrm{ng} / \mathrm{ml}$ for $5 \mathrm{~min}$ ), the frequency, but not the amplitude, of mEPSCs significantly increased (Fig. 5A), similar to that seen in $\mathrm{Chrd}^{-1-}$ slices. Interestingly, when BMP2 was perfused onto slices at the same concentration and rate as BMP6, we saw no effect on mEPSC frequency or amplitude (Fig. 5B). In tissue culture signaling assays, BMP6 and BMP2 produced comparable levels of Smad phosphorylation, indicating that each ligand is active for

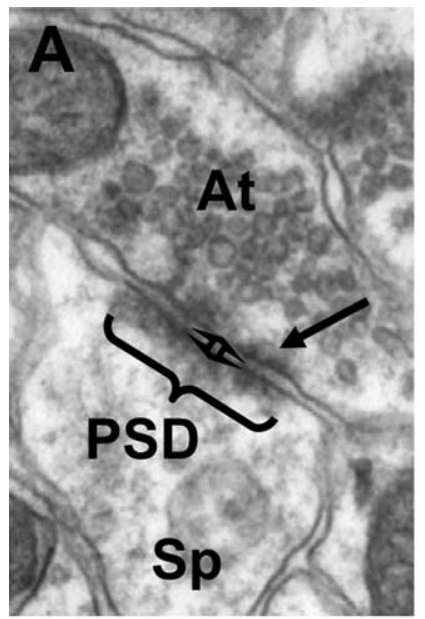

\section{Chrd +/+}

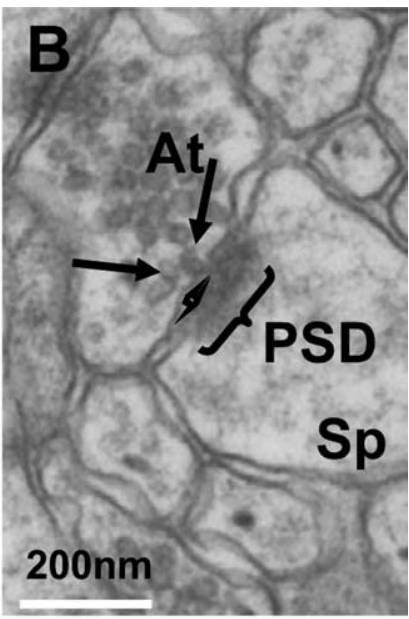

Chrd -/-
Figure 4. Ultrastructural change of hippocampal synapses in $\mathrm{Chrd}^{-/-}$mice. A, Transmission electron microscopy of asymmetric synapse of $\mathrm{Chrd}^{+/+}$in CA 1 region; symbol $\uparrow$ points to the synaptic cleft, and symbol $\{$ indicates the length of active zone. Arrows point to docked vesicles. At, Axon terminal; Sp, spine; PSD, postsynaptic density. B, Asymmetric synapse of $\mathrm{Chrd}^{-/-}$in CA1 region. (Values are listed in Table 1.)

Table 1. Quantification of ultrastructural parameters of hippocampal synapses

\begin{tabular}{lcc}
\hline & $\mathrm{Chrd}^{+/+}$ & $\mathrm{Chrd}^{-/-}$ \\
\hline Total number of vesicles/bouton & $26.4 \pm 2.5$ & $24.5 \pm 2.4$ \\
Docked vesicles/synapse & $1.2 \pm 0.2$ & $1.7 \pm 0.2$ \\
Length of active zone $(\mu \mathrm{m})$ & $0.47 \pm 0.04$ & $0.49 \pm 0.11$ \\
Docked vesicles/active zone length (DV/ $\mu \mathrm{m})$ & $2.88 \pm 0.71$ & $4.97 \pm 0.52^{*}$ \\
Width of synaptic cleft $(\mathrm{nm})$ & $60.9 \pm 4.2$ & $46.5 \pm 5.2^{*}$
\end{tabular}

$\mathrm{Chrd}^{-/-}$synapses of hippocampal CA1 region have more docked vesicles per active zone length $(p=0.01)$ and a narrower synaptic cleft $(p=0.04)$.

binding and canonical signal transduction (supplemental Fig. 1, available at www.jneurosci.org as supplemental material). Therefore, the difference in activity of these ligands on slices is not simply because one ligand is less active then the other for canonical signaling.

To determine whether downregulation of BMP signaling in acute slices results in the opposite effect on mini frequency, we also perfused recombinant chordin protein onto wild-type slices. In this case, we could not detect any significant change in mEPSC frequency (supplemental Fig. 2, available at www.jneurosci.org as supplemental material). It is also possible that endogenous BMP1, a metalloprotease that cleaves chordin, inactivates much of the exogenous chordin. However, cell signaling assays also showed that this commercial chordin protein does not significantly block BMP signaling in the concentration range used (supplemental Fig. 3, available at www.jneurosci.org as supplemental material). As an alternative, we examined the effects of Noggin, another structurally unrelated BMP inhibitor. In signaling assays, Noggin was a much more potent inhibitor than chordin (supplemental Fig. 3, available at www.jneurosci.org as supplemental material). We tested two physiological concentrations of Noggin on the acute slices. With the lower concentration $(100 \mathrm{ng} / \mathrm{ml})$, there was no significant effect on miniature events (supplemental Fig. 2, available at www.jneurosci.org as supplemental material), but perfusion of Noggin at $200 \mathrm{ng} / \mathrm{ml}$ significantly decreased the frequency of mEPSC ( $p<0.05$, paired $t$ test) (Fig. $5 C$ ).

To test whether acutely enhanced BMP signaling could affect synaptic plasticity, we also incubated wild-type slices in 200 

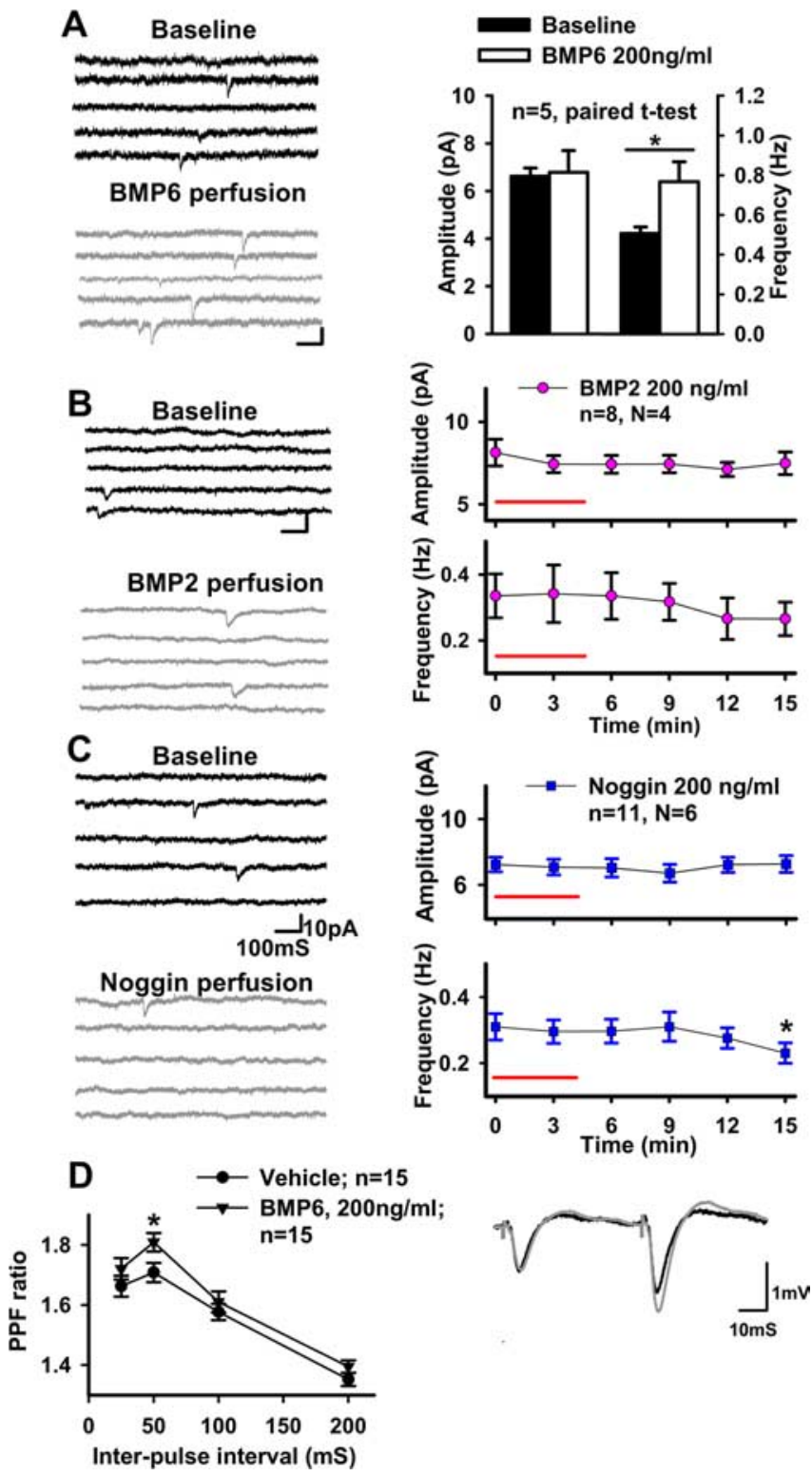

Figure 5. Effect of perfusion of BMPs and BMP antagonists on $m E P S C s$ and PPF. A, Perfusion of BMP6 on $\mathrm{Chrd}^{+/+}$slices increased the frequency but not the amplitude of mEPSCs. Left shows representative sweeps from control and 15 min after treatment. Right shows significant increase of frequency but not amplitude after perfusion of BMP6. $B, B M P 2$ at a similar concentration had no effect on mEPSCs after 15 min perfusion. Representative traces of mEPSCs are shown on the left. Right shows time-lapse change of amplitude and frequency of mEPSCs at 3 min analysis interval. There is no significant change of either mEPSCs amplitude or frequency. $\boldsymbol{C}$, Perfusion of Noggin, an antagonist of BMP signaling, inhibited release possibilities but not amplitude of mEPSC after $15 \mathrm{~min}$ (paired $t$ test, $p<0.05$ ). D, PPF of wild-type slices treated with BMP6. Slices were incubated in a mini-interface chamber with $200 \mathrm{ng} / \mathrm{ml} \mathrm{BMP6}$ or vehicle for $30 \mathrm{~min}$. They were then transferred to an interface recording chamber to test paired-pulse facilitation. At 50 mS ISI, BMP6-treated slices showed higher PPF. Normalized representative traces were shown as inset.

ng/ml BMP6 for $30 \mathrm{~min}$ and recorded paired-pulse facilitation. Like $\mathrm{Chrd}^{-/-}$slices, BMP6-treated slices showed a higher PPF than control slices but only at $50 \mathrm{mS}$ ISI (Fig. 5D). Because addition of exogenous BMP6 enhances short-term plasticity and mEPSC frequency similar to that seen in Chrd mutants, these results are consistent with the view that loss of chordin likely produces its effects by enhancing signaling by certain BMP ligands within the hippocampus.
Chrd $^{-/-}$hippocampal slices show an increase of highfrequency stimulation-induced LTP

LTP is widely studied throughout different regions of the CNS and is a well accepted cellular model for learning and memory (Lynch, 2004). We used both extracellular field recordings and whole-cell recordings to test whether removal of chordin would disturb normal LTP induction and expression in the hippocampus based on a presynaptic mechanism. With a standard HFS protocol $(100 \mathrm{~Hz}, 1 \mathrm{~s}, 100$ pulses totally), a higher field LTP is found in chordin mutant slices $1 \mathrm{~h}$ after induction (last $20 \mathrm{~min}$ average value fEPSP slope of $149.2 \pm 7.7$ vs $126.7 \pm 4.9 ; p=0.02$ ) (Fig. 6A). In general, low-frequency presynaptic stimulation (1 $\mathrm{Hz}, 100 \mathrm{~s}, 100$ pulses total) coupled with depolarization of the CA1 soma $(0 \mathrm{mV})$ results in a more sensitive postsynapticspecific LTP, and this protocol affects transmitter release less from presynaptic sites than does high-frequency stimulation (HFS) (Xu et al., 2000). Using such conditions, we induced the same level of LTP from both genotypes (140.2 \pm 10.0 vs $134.9 \pm$ $11.9 ; p=0.70$ ) (Fig. 6B). The non-enhanced LTP in $\mathrm{Chrd}^{-/-}$ animals obtained from these patch-clamp recordings is, once again, more consistent with chordin affecting a presynaptic event.

TBS is thought to be a more physiologically relevant LTP induction protocol that mimics synaptic transmission paired with firing of postsynaptic neurons. It can induce both NMDA receptor-dependent LTP and a presynaptic calcium channelsensitive LTP (Zakharenko et al., 2003). We found that a TBS protocol produced similar levels of LTP in both wild-type and $\mathrm{Chrd}^{-1-}$ animals (Fig. 7A). Therefore, it appears that only a protocol that maximally activates presynaptic release can induce higher LTP in $\mathrm{Chrd}^{-/-}$slices.

To further examine this idea, we measured the depolarization envelope elicited by synaptic stimulation during the induction of LTP. For a $1 \mathrm{~s}, 100 \mathrm{~Hz}$ protocol, $\mathrm{Chrd}^{-/-}$slices showed significantly larger normalized area compared with $\mathrm{Chrd}^{+/+}$slices $(1.58 \pm 0.08$ vs $1.26 \pm 0.07 \mathrm{mV} / \mathrm{mS} ; p<0.01)$. However, one train of the TBS protocol (40 pulses in $2 \mathrm{~s}$ ) triggered a similar depolarization envelope from the two genotypes ( $1.32 \pm 0.06 \mathrm{vs}$ $1.19 \pm 0.07 \mathrm{mV} / \mathrm{mS} ; p=0.17)$. Together with the evidence for enhanced presynaptic function in $\mathrm{Chrd}^{-/-}$mice, these data suggest that the observed increases in LTP magnitude are likely a function of the enhanced depolarization provided by particularly robust glutamate release occurring in $\mathrm{Chrd}^{-/-}$slices during extended high-frequency stimulation $(1 \mathrm{~s}, 100 \mathrm{~Hz})$.

To test whether loss of chordin influenced LTP maintenance over time, we used several different stimulus protocols and examined LTP $3 \mathrm{~h}$ after induction. Using a four-train protocol, we found no difference in the maintenance LTP induced in $C h r d^{-1-}$ slices compared with wild type (Fig. $7 B$ ). However, because weaker stimulation $(1 \mathrm{~s}, 100 \mathrm{~Hz})$ but not stronger TBS stimulation could induce higher LTP in $\mathrm{Chrd}^{-/-}$slices, we reasoned that the induction might be saturated by the strong stimulus. Therefore, we also examined late-phase LTP using the weaker $1 \mathrm{~s}, 100$ $\mathrm{Hz}$ protocol and found that, in our submerged recording chamber, $\mathrm{Chrd}^{-1-}$ slices expressed sustained LTP for $3 \mathrm{~h}$ after a single train of stimulation (Fig. 7C), whereas $\mathrm{Chrd}^{+/+}$slices could not.

Together, these results suggest that $\mathrm{Chrd}^{-/-}$mice have intact NMDA and calcium channel-dependent LTP because the TBS protocol results in similar levels of LTP in these slices compared with controls. The inability to induce an enhanced late-phase LTP in $\mathrm{Chrd}^{-/-}$slices by a four-train HFS protocol also suggests that the induction process is saturated using a four-train stimulus. In contrast, however, we suggest that the higher LTP induced 
by single-train HFS derives from an enhancement of presynaptic function in $\mathrm{Chrd}^{-/-}$animals that is strong enough to reach the threshold for late-phase LTP induction, whereas in wild-type animals it is not.

$\mathrm{Chrd}^{-/-}$mice exhibit impaired cognitive behavior

To determine whether the enhancement of presynaptic function in $\mathrm{Chrd}^{-/-}$mutants could affect cognitive behavior, we initially tested $\mathrm{Chrd}^{-/-}$mutant behavior using a two-trial Y-maze test in which performance relies on an innate tendency of a mouse to explore a novel environment but not on learning a new behavior or rule (Dellu et al., 1992). During the recall trial, which is $3 \mathrm{~h}$ after the acquisition phase, $\mathrm{Chrd}^{-1-}$ animals entered the formerly closed (now novel) arm of the Y-maze less frequently than their littermate controls (Fig. 8A).

The altered performance of $\mathrm{Chrd}^{-1-}$ mice might result from disturbed spatial recognition or a distortion of a basic instinctive behavior, such as rapid adaptation or a diminished exploratory instinct toward a new environment. To examine these issues further, we performed a onetrail open-field test with a novel object placed near one corner of the box. The overall ambulatory speed of $\mathrm{Chrd}^{-/-}$mice was no different from wild type (Fig. $8 \mathrm{~B}$ ). They also entered into an arbitrary circle area in the center of the open field with the same frequency and dwelled in the center with the same duration as wild-type mice. However, $\mathrm{Chrd}^{-/-}$mice showed hyperactivity inside the circle area. They ran faster than $\mathrm{Chrd}^{+/+}$mice in the center of the open field. Interestingly, $\mathrm{Chrd}^{-/-}$mice also showed less sniffing behavior to a novel object inside the box during the 15 min test (Fig. $8 B$, first group of bars). These results are consistent with either a decrease in innate exploratory behavior or quicker habituation to the new environment.

We next tested $\mathrm{Chrd}^{-/-}$animals in a standard Morris water maze, a well characterized hippocampal-dependent spatial learning and memory test (Morris, 1984). At the beginning of the training period, there was no difference between $\mathrm{Chrd}^{-/-}$and $\mathrm{Chrd}^{+/+}$littermate mice in their ability to find a visually cued platform within the water. However, with spatial extramaze cues, $\mathrm{Chrd}^{-1-}$ mice showed a significantly improved ability to find the hidden platform. On average, it took them dramatically less time to escape from the water pool on the second day $(p<0.001)$ (Fig. $8 C$ ). Measurement of the swimming speed showed no significant difference between genotypes $(200.5 \pm 8.4 \mathrm{vs} 180.6 \pm 6.8 \mathrm{~mm} / \mathrm{S} ; p>$ 0.05). After training for $10 \mathrm{~d}$, both groups of mice performed the task equally well. To test for relearning and learning flexibility, the platform was switched to an adjacent quadrant inside the genotypes after $30 \mathrm{~min}$.
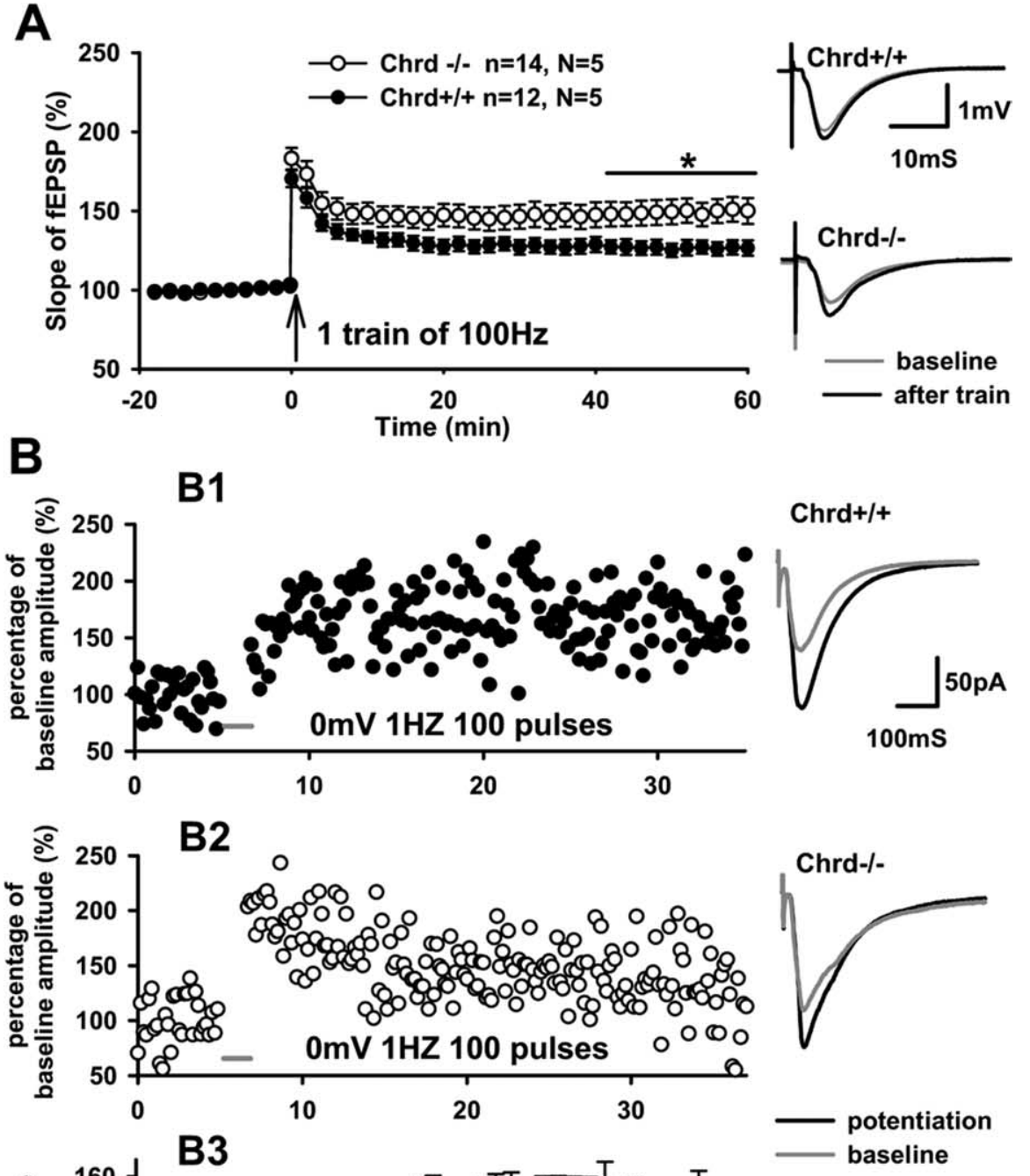

Figure 6. Increase in high-frequency tetanus-induced LTP in $\mathrm{Chrd}^{-/-}$slices. A, $\mathrm{Chrd}^{-/-}$mice show higher LTP with $100 \mathrm{~Hz}$, $1 \mathrm{~s}$ protocol. Mean slope of fEPSPs recorded $0-20 \mathrm{~min}$ before induction of LTP was set as baseline. Number of analyzed slices $(n)$ and animals $(N)$ are indicated. Representative sweeps are shown on the right. $\boldsymbol{B}$, Pairing protocol-induced postsynaptic-specific LTP is normal in $\mathrm{Chrd}^{-/-}$slices. B1, Sample recording from $\mathrm{Chrd}^{+/+}$slice. B2, Sample recording from Chrd ${ }^{-/-}$slice. B3, Accumulated data from two genotypes for pairing protocol-induced LTP. As shown in the right, there is no difference between

pool. Under these conditions, both genotypes showed the same acquisition curve for the new task in the successive days. To evaluate spatial memory, two probe tests were given on days 11 and $18,24 \mathrm{~h}$ after the end of learning or relearning trails. In this test, the platform was removed and the duration of time spent in each quadrant was measured. Both groups showed a similar high preference for exploring the former platform-containing quadrant (Fig. $8 \mathrm{D}$ ). In summary, these results indicated that $\mathrm{Chrd}^{-/-}$mice have enhanced hippocampal-dependent spatial learning and less exploratory activity in a novel environment but no changes in long-term memory or motor processes. 

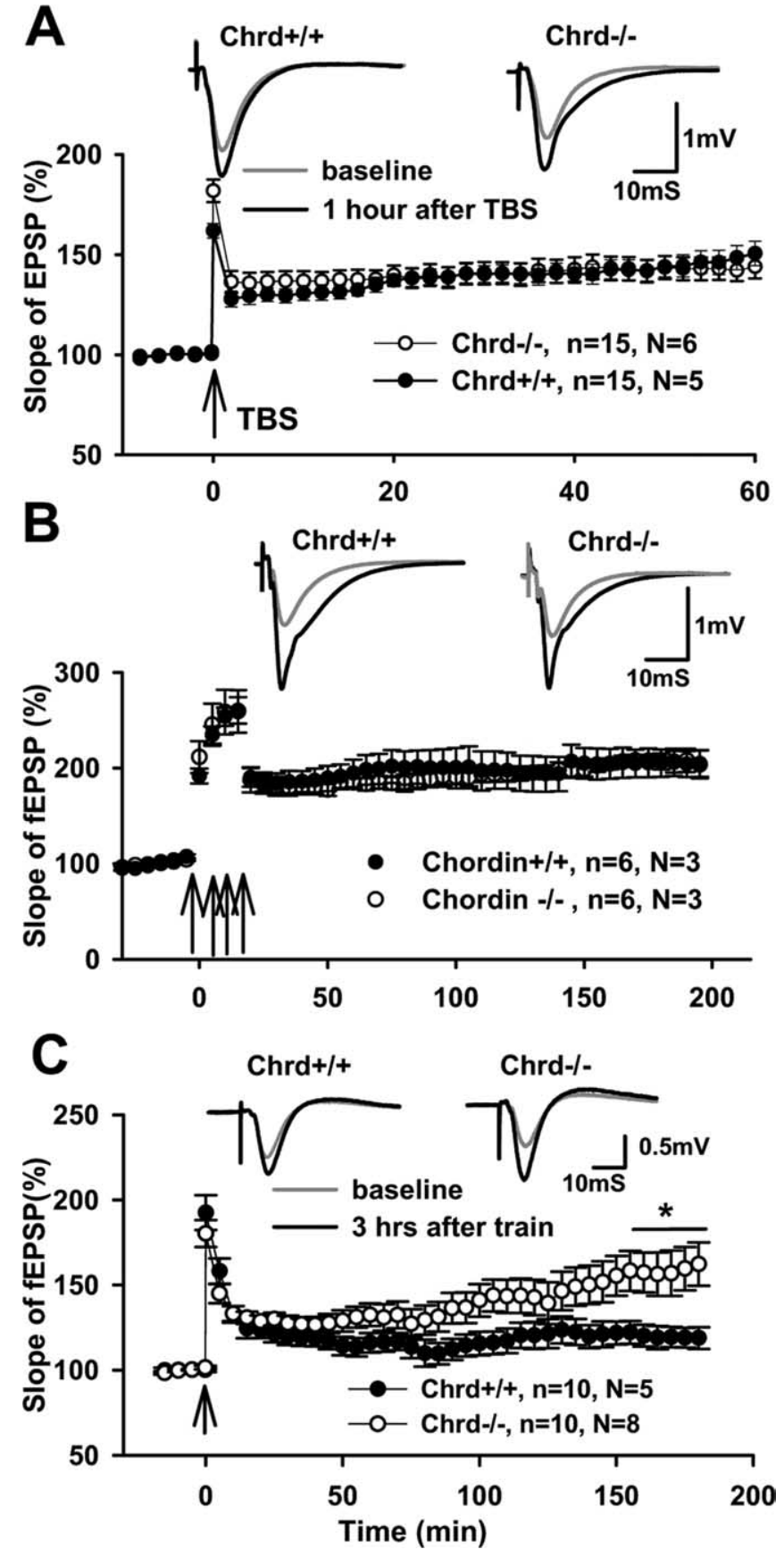

Figure 7. Transition from early-phase LTP to late-phase LTP. A, TBS protocol induced a similar level of LTP in $\mathrm{Chrd}^{-/-}$and $\mathrm{Chrd}^{+/+}$slices. Mean amplitudes of fEPSPs recorded 0 -10 min before induction of LTP were set as a baseline. Above the summary plot are shown an average baseline sweep and a sweep $1 \mathrm{~h}$ after induction. $\boldsymbol{B}, \mathrm{A}$ train of $100 \mathrm{~Hz}$ in $1 \mathrm{~s}$ given four times with a 5 min interval induces late-phase LTP at the same level from both $\mathrm{Chrd}^{-1-}$ and $\mathrm{Chrd}^{+/+}$slices. Averaged sweeps of baseline and $3 \mathrm{~h}$ after induction are shown above the accumulated plot. C, In a submerged recording chamber, early-phase LTP induced by one train of $100 \mathrm{~Hz}$ lasts longer than $3 \mathrm{~h}$. The average slope of fEPSP of the last 20 min showed a significant difference between $\mathrm{Chrd}^{-/-}$and $\mathrm{Chrd}^{+/+}$slices. (158.8 \pm 12.8 vs $120.6 \pm 5.7 ; p<0.05, t$ test)

\section{Discussion}

The studies we describe here indicate that loss of the chordin, a potent inhibitor of BMP signaling that alters synaptic activity in the mouse hippocampus resulting in learning and behavior changes, and its invertebrate homolog Sog, are key regulators of BMP signaling in early development (Garcia Abreu et al., 2002).
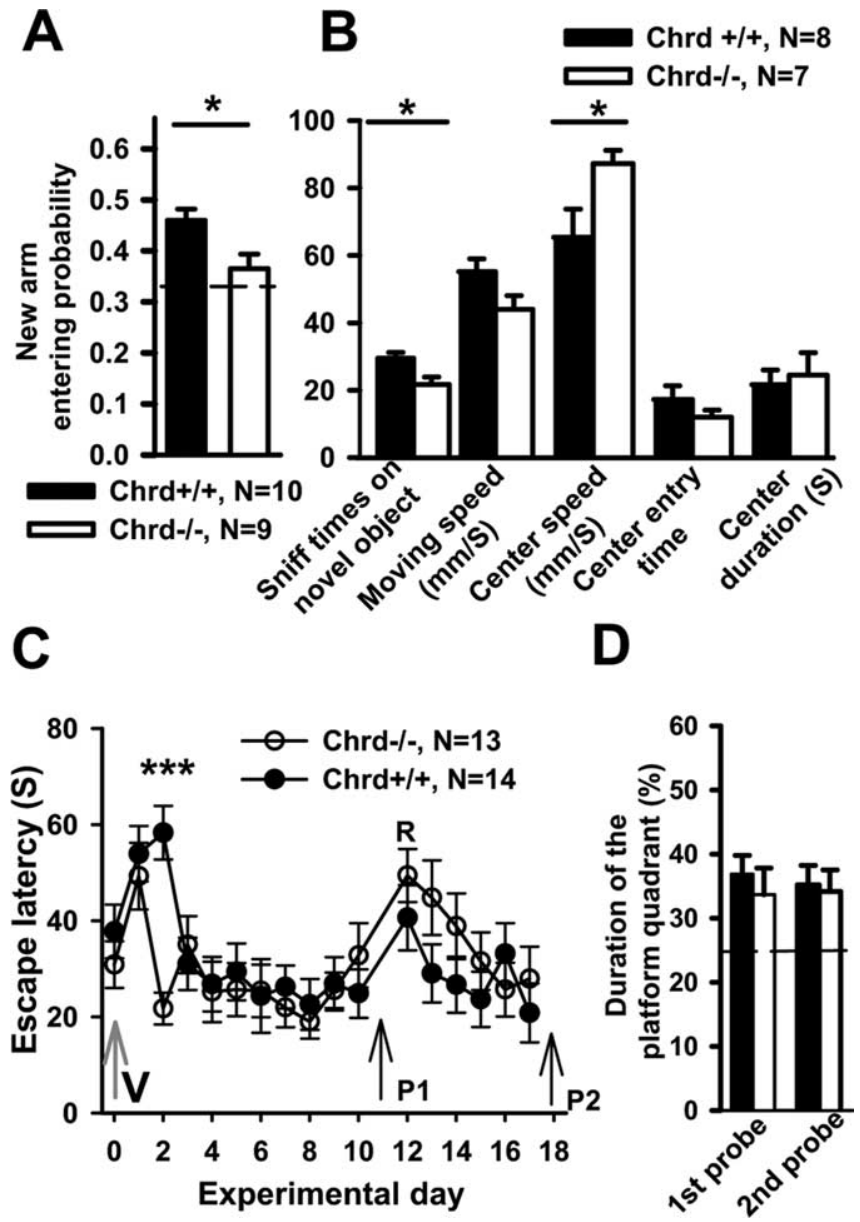

Figure 8. Cognitive behavior in $\mathrm{Chrd}^{-/-}$mice. A, Chrd ${ }^{-1-}$ mice showed less entry time to the formerly closed arm during a recall test of $Y$-maze. Dashed line is the random possibility for the new arm 0.33. B, Chrd ${ }^{-1-}$ mice showed less interaction with a novel object and faster running speed inside the center of an open field. Chrd ${ }^{-1-}$ mice show no difference in locomotive speed in areas outside the center compared with $\mathrm{Chrd}^{+/+}$mice. $\mathrm{Chrd}^{-/-}$mice showed no significant change of center entry time and center staying time. $\mathbf{C}$, In a water maze test, $\mathrm{Chrd}^{-/-}$mice showed shorter escape latency on the second day of learning. ( Shows the escape latency plotted against training day. 0 n day 0 , (V) refers to cued platform; on days 1-17, a hidden platform was used. $\mathrm{P} 1$ and $\mathrm{P} 2$ indicate day 11 probe test and day 18 probe test. R means start of reversal test, in which the hidden platform was moved to an adjacent quadrant. $\boldsymbol{D}, 0$ n day 11 , the platform was removed from the pool and mice were given $60 \mathrm{~s}$ to explore the pool. Both $\mathrm{Chrd}^{-/-}$and $\mathrm{Chrd}^{+/+}$mice showed a similar higher preference for exploring the quadrant in which the platform used to be located. After the reversal on day 13 , a second probe test was given on day 18 , and again no difference between genotypes is seen in their preference for exploring the quadrant in which the platform used to be located. Dashed line indicates the $25 \%$ possibility of random selection for the target quadrant.

Approximately 50\% of $\mathrm{Chrd}^{-/-}$null mutants survive to produce healthy breeding adults, likely attributable to functional redundancy with other BMP inhibitors such as Noggin (Bachiller et al., 2000). Our morphological analysis does not support a role for chordin in regulating spinogenesis and dendritogenesis in the hippocampus. However, at the ultrastructure level, $\mathrm{Chrd}^{-/-}$ mice showed abnormal presynaptic structural organization. There was an increase of docked vesicles per active zone length and a smaller synaptic cleft width. Because the shape of axon terminal determines the vesicle release probability and cycling speed (Xu-Friedman and Regehr, 2004), the change of distribution of vesicles and synaptic width might contribute to the enhanced short-term plasticity and spatiotemporal processing (Fortune and Rose, 2001) that we see in $\mathrm{Chrd}^{-/-}$mice. Although 
it is not entirely clear whether these ultrastructural changes are the result of earlier neonatal developmental differences or whether they represent later effects brought about by enhanced BMP signaling in the adult, we favor the latter because we can replicate several of the physiological effects of genetic chordin loss, such as enhanced PPF and mini frequency, by perfusing slices with BMPs. In addition, downregulation of BMP signaling by perfusion of Noggin, a potent BMP inhibitor, decreased mEPSC frequency.

Interestingly, the ultrastructural changes and differences in physiology in $\mathrm{Chrd}^{-/-}$mice are the opposite of what is seen at the Drosophila NMJ when BMP signaling is compromised. In Drosophila, a reduction in BMP signaling leads to loss of adhesion between the presynaptic and postsynaptic membranes and a decrease in mini release probability (Aberle et al., 2002; Marques et al., 2002). Although these results are from different organisms, they are consistent with the view that loss of chordin enhances BMP signaling in the nervous system.

\section{Are the chordin effects on hippocampal function mediated by a canonical BMP signaling pathway?}

Although we show here that all of the pyramidal cells in the hippocampus exhibit high levels of pSmad accumulation, we were unable to demonstrate any enhancement in the overall level of Smad1/5 phosphorylation in $\mathrm{Chrd}^{-/-}$animals by either immunohistochemistry or Western blots. We favor noncanonical pathway involvement for several reasons. First, the effects we see during perfusion of BMPs on slices are rapid and inconsistent with the time that would be required for a genomic-based transcriptional response. Second, hippocampal specific removal of Smad4, the common Smad that is thought to be required for most Smad-dependent transcriptional responses, produces no significant electrophysiological changes in the dentate gyrus (Zhou et al., 2003) or in CA1, nor does its removal alter performance in the Morris water maze (Sun et al., 2006).

In both vertebrates and Drosophila, the association of the BMP type II receptor with LIM kinase mediates changes in the cytoskeletal architecture at the synapse (Foletta et al., 2003; LeeHoeflich et al., 2004; Eaton and Davis, 2005), which could potentially contribute to the abnormal presynaptic ultrastructure in Chrd ${ }^{-/-}$mice and the effect of BMP6 on transmitter release through a non-Smad-dependent mechanism.

Another likely target for a noncanonical BMP effect is the MAPK-dependent phosphorylation of synapsin I. Mice expressing a constitutively active form of $\mathrm{H}$-Ras exhibited several presynaptic changes similar to $\mathrm{Chrd}^{-/-}$mice (Kushner et al., 2005). The presynaptic effect of $\mathrm{H}$-Ras activation is mediated by synapsin I, consistent with alterations in vesicle trafficking as being the primary mechanism behind the changes. The fact that TGF- $\beta 1$ could phosphorylate synapsin I through MAPK (Chin et al., 2002, 2006) suggests that the serine/threonine kinase activity of $\mathrm{BMP}$ receptors might also be able to mediate vesicle release machinery through this mechanism. The colocalization of BMPRII and synapsin I is consistent with this possibility (Fig. $1 E, F$ ).

Another interesting attribute of the BMP signaling effects is the distinction in the responses to different ligand subfamilies. Although we see that perfusion of BMP6 can replicate some of the loss of chordin effects, BMP2, which is equally or more active on a per mole basis for stimulating Smad phosphorylation in tissue culture, is unable to stimulate PPF or enhance mini release on hippocampal slices. Similarly, BMP2 was unable to regulate ionotropic glutamate receptor activity in the retina compared with BMP7 (Shen et al., 2004). Drosophila Gbb (glass-bottom boat), a close relative of BMP6 and BMP7, regulates both NMJ and interneuronal synapse activity, whereas Dpp (decapentaplegic, an ortholog of BMP2 and BMP4, has no effect (Baines, 2004). Although not examined in great detail, these ligand subfamilies (BMP2/4 and BMP5/6/7) appear to have differential binding affinities for different combinations of BMP receptors, which could explain their different properties in regulating neuronal plasticity.

\section{Presynaptic plasticity and function of BMPs}

Short-term plasticity is very critical for computational functions in the cortical network (Abbott and Regehr, 2004). Chrd ${ }^{-/-}$mutants showed normal basic excitatory synaptic transmission in CA1 but produced novel presynaptic phenotypes in which both $\mathrm{PPF}$ and the frequency of mEPSCs increased significantly. This phenomenon conflicts with classical quantal release theory. In principle, the increase of release probability or higher frequency of mEPSC should be accompanied by a decrease instead of an increase in PPF. However, if BMP signaling regulates vesicle fusion, then it is reasonable to see an increase of mEPSC frequency and PPF at the same time, similar to that seen in Rab3a knock-out mutants (Geppert et al., 1997) or the constitutively activated H-Ras example described above.

Although postsynaptic mechanisms have received considerable attention (Malinow and Malenka, 2002), examples of presynaptic contributions to LTP have also been described (Choi et al., 2003; Kushner et al., 2005; Powell, 2006), and a unified model of presynaptic and postsynaptic contributions to LTP at the CA1 hippocampal synapses has recently been proposed (Lisman and Raghavachari, 2006). Our results also suggest that upregulation of vesicle release can enhance LTP induction under certain conditions. High-frequency stimulation of afferent fibers $(100 \mathrm{~Hz}$, $1 \mathrm{~s}$ ) induced significantly larger LTP in $\mathrm{Chrd}^{-/-}$hippocampal slices than in controls. Conversely, low-frequency stimulation (paired with direct postsynaptic depolarization) or short bursts of afferent activation (TBS) induced the same level of potentiation in $\mathrm{Chrd}^{-/-}$slices and controls. Not only do we find that LTP is selectively enhanced under conditions in which demands on the presynaptic neurons are high (i.e., $100 \mathrm{~Hz}, 1 \mathrm{~s}$ ), but also that these conditions elicit a magnified depolarization envelope whereas others (i.e., TBS) do not. These data suggest that LTP augmentation in $\mathrm{Chrd}^{-/-}$mutants is attributable to enhancement of presynaptic release properties.

TBS is a popular and "physiological" paradigm for LTP induction that is based on the close interaction of theta $(4-8 \mathrm{~Hz})$ and gamma $(30-100 \mathrm{~Hz})$ oscillations observed in the hippocampus in vivo. However, evidence also suggests that ongoing gamma frequency activity may contribute to memory encoding and selective attention (Varela et al., 2001; Womelsdorf et al., 2006). Our study provides an example of a correlation between LTP induced by extended gamma-frequency stimulation $(100 \mathrm{~Hz}, 1 \mathrm{~s})$ and spatial learning. Thus, the degree to which this high-frequency protocol may mimic in vivo plasticity mechanisms deserves further study.

Although $\mathrm{Chrd}^{-/-}$mice show improved learning in the water maze test, they showed impairment in the Y-maze, another spatial memory task. One obvious difference between two tests is that Y-maze is based on both intact spatial memory, knowing which arm is new according to the spatial cues around the maze, but also on the innate behavior to explore a new environment. The abnormal performance of $\mathrm{Chrd}^{-/-}$in the Y-maze might result from decreased innate exploratory/curiosity behavior. Similarly, during the open-field test, $\mathrm{Chrd}^{-1-}$ mice interacted less 
with a novel object, perhaps indicating they had a decreased curiosity for new objects. However, it also seems possible that, as in the water maze test, $\mathrm{Chrd}^{-1-}$ mice simply learn faster and require fewer encounters before they no longer perceive the new Y-maze arm or object as novel. Additional studies will be required to distinguish between these possibilities.

\section{Are other extracellular regulators of BMP activity also involved in mediating neural plasticity?}

Chordin is unusual among BMP inhibitors because its activity is regulated by metalloproteases of the BMP-1/Tld (tolloid) family. In developmental contexts, BMP-1/Tld-like enzymes degrade chordin and thereby enhance BMP signaling (Blader et al., 1997; Marques et al., 1997). It is interesting to note in this regard that induction of long-term sensitization in Aplysia by application of serotonin or by behavioral training both stimulate expression of a BMP-1/Tld homolog (Liu et al., 1997). Might it be that long-term sensitization stimulated by serotonin or behavioral training in Aplysia is enhanced or reinforced by up regulating BMP signaling through degradation of chordin by BMP-1/Tld-like proteases? Clearly, additional in vivo manipulation of BMP signaling pathway components will be required to fully understand its role in modulating synaptic plasticity in different organisms.

\section{References}

Abbott LF, Regehr WG (2004) Synaptic computation. Nature 431:796-803. Aberle H, Haghighi AP, Fetter RD, McCabe BD, Magalhaes TR, Goodman CS (2002) wishful thinking encodes a BMP type II receptor that regulates synaptic growth in Drosophila. Neuron 33:545-558.

Bachiller D, Klingensmith J, Kemp C, Belo JA, Anderson RM, May SR, McMahon JA, McMahon AP, Harland RM, Rossant J, De Robertis EM (2000) The organizer factors Chordin and Noggin are required for mouse forebrain development. Nature 403:658-661.

Bachiller D, Klingensmith J, Shneyder N, Tran U, Anderson R, Rossant J, De Robertis EM (2003) The role of chordin/Bmp signals in mammalian pharyngeal development and DiGeorge syndrome. Development 130:3567-3578.

Baines RA (2004) Synaptic strengthening mediated by bone morphogenetic protein-dependent retrograde signaling in the Drosophila CNS. J Neurosci 24:6904-6911.

Blader P, Rastegar S, Fischer N, Strahle U (1997) Cleavage of the BMP-4 antagonist chordin by zebrafish tolloid. Science 278:1937-1940.

Chin J, Angers A, Cleary LJ, Eskin A, Byrne JH (2002) Transforming growth factor betal alters synapsin distribution and modulates synaptic depression in Aplysia. J Neurosci 22:RC220(1-6).

Chin J, Liu RY, Cleary LJ, Eskin A, Byrne JH (2006) TGF-beta1-induced long-term changes in neuronal excitability in Aplysia sensory neurons depend on MAPK. J Neurophysiol 95:3286-3290.

Choi S, Klingauf J, Tsien RW (2003) Fusion pore modulation as a presynaptic mechanism contributing to expression of long-term potentiation. Philos Trans R Soc Lond B Biol Sci 358:695-705.

Dellu F, Mayo W, Cherkaoui J, Le Moal M, Simon H (1992) A two-trial memory task with automated recording: study in young and aged rats. Brain Res 588:132-139.

Derynck R, Zhang YE (2003) Smad-dependent and Smad-independent pathways in TGF-beta family signalling. Nature 425:577-584.

Dudu V, Bittig T, Entchev E, Kicheva A, Julicher F, Gonzalez-Gaitan M (2006) Postsynaptic mad signaling at the Drosophila neuromuscular junction. Curr Biol 16:625-635.

Eaton BA, Davis GW (2005) LIM Kinase1 controls synaptic stability downstream of the type II BMP receptor. Neuron 47:695-708.

Foletta VC, Lim MA, Soosairajah J, Kelly AP, Stanley EG, Shannon M, He W, Das S, Massague J, Bernard O (2003) Direct signaling by the BMP type II receptor via the cytoskeletal regulator LIMK1. J Cell Biol 162:1089-1098.

Fortune ES, Rose GJ (2001) Short-term synaptic plasticity as a temporal filter. Trends Neurosci 24:381-385.

Garcia Abreu J, Coffinier C, Larrain J, Oelgeschlager M, De Robertis EM (2002) Chordin-like CR domains and the regulation of evolutionarily conserved extracellular signaling systems. Gene 287:39-47.
Geppert M, Goda Y, Stevens CF, Sudhof TC (1997) The small GTP-binding protein Rab3A regulates a late step in synaptic vesicle fusion. Nature 387:810-814.

Gomes WA, Mehler MF, Kessler JA (2003) Transgenic overexpression of BMP4 increases astroglial and decreases oligodendroglial lineage commitment. Dev Biol 255:164-177.

Harris KM, Sultan P (1995) Variation in the number, location and size of synaptic vesicles provides an anatomical basis for the nonuniform probability of release at hippocampal CA1 synapses. Neuropharmacology 34:1387-1395.

Kushner SA, Elgersma Y, Murphy GG, Jaarsma D, van Woerden GM, Hojjati MR, Cui Y, LeBoutillier JC, Marrone DF, Choi ES, De Zeeuw CI, Petit TL, Pozzo-Miller L, Silva AJ (2005) Modulation of presynaptic plasticity and learning by the $\mathrm{H}$-ras/extracellular signal-regulated kinase/synapsin I signaling pathway. J Neurosci 25:9721-9734.

Law JW, Lee AY, Sun M, Nikonenko AG, Chung SK, Dityatev A, Schachner M, Morellini F (2003) Decreased anxiety, altered place learning, and increased CA1 basal excitatory synaptic transmission in mice with conditional ablation of the neural cell adhesion molecule L1. J Neurosci 23:10419-10432.

Lee-Hoeflich ST, Causing CG, Podkowa M, Zhao X, Wrana JL, Attisano L (2004) Activation of LIMK1 by binding to the BMP receptor, BMPRII, regulates BMP-dependent dendritogenesis. EMBO J 23:4792-4801.

Lein P, Johnson M, Guo X, Rueger D, Higgins D (1995) Osteogenic protein-1 induces dendritic growth in rat sympathetic neurons. Neuron 15:597-605.

Lisman J, Raghavachari S (2006) A unified model of the presynaptic and postsynaptic changes during LTP at CA1 synapses. Sci STKE 2006:re11.

Liu QR, Hattar S, Endo S, MacPhee K, Zhang H, Cleary LJ, Byrne JH, Eskin A (1997) A developmental gene (Tolloid/BMP-1) is regulated in Aplysia neurons by treatments that induce long-term sensitization. J Neurosci 17:755-764.

Lynch MA (2004) Long-term potentiation and memory. Physiol Rev 84:87-136.

Malinow R, Malenka RC (2002) AMPA receptor trafficking and synaptic plasticity. Annu Rev Neurosci 25:103-126.

Marques G, Musacchio M, Shimell MJ, Wunnenberg-Stapleton K, Cho KW, O'Connor MB (1997) Production of a DPP activity gradient in the early Drosophila embryo through the opposing actions of the SOG and TLD proteins. Cell 91:417-426.

Marques G, Bao H, Haerry TE, Shimell MJ, Duchek P, Zhang B, O’Connor MB (2002) The Drosophila BMP type II receptor Wishful Thinking regulates neuromuscular synapse morphology and function. Neuron 33:529-543.

McCabe BD, Marques G, Haghighi AP, Fetter RD, Crotty ML, Haerry TE, Goodman CS, O'Connor MB (2003) The BMP homolog Gbb provides a retrograde signal that regulates synaptic growth at the Drosophila neuromuscular junction. Neuron 39:241-254.

Mehler MF, Mabie PC, Zhang D, Kessler JA (1997) Bone morphogenetic proteins in the nervous system. Trends Neurosci 20:309-317.

Morris R (1984) Developments of a water-maze procedure for studying spatial learning in the rat. J Neurosci Methods 11:47-60.

Moustakas A, Heldin CH (2005) Non-Smad TGF-beta signals. J Cell Sci 118:3573-3584.

Pappano WN, Scott IC, Clark TG, Eddy RL, Shows TB, Greenspan DS (1998) Coding sequence and expression patterns of mouse chordin and mapping of the cognate mouse chrd and human CHRD genes. Genomics $52: 236-239$.

Piccolo S, Sasai Y, Lu B, De Robertis EM (1996) Dorsoventral patterning in Xenopus: inhibition of ventral signals by direct binding of chordin to BMP-4. Cell 86:589-598.

Powell CM (2006) Gene targeting of presynaptic proteins in synaptic plasticity and memory: across the great divide. Neurobiol Learn Mem 85:2-15.

Rawson JM, Lee M, Kennedy EL, Selleck SB (2003) Drosophila neuromuscular synapse assembly and function require the TGF-beta type I receptor saxophone and the transcription factor Mad. J Neurobiol 55:134-150.

Rhinn M, Picker A, Brand M (2006) Global and local mechanisms of forebrain and midbrain patterning. Curr Opin Neurobiol 16:5-12.

Sasai Y (2001) Regulation of neural determination by evolutionarily conserved signals: anti-BMP factors and what next? Curr Opin Neurobiol $11: 22-26$ 
Scott IC, Steiglitz BM, Clark TG, Pappano WN, Greenspan DS (2000) Spatiotemporal expression patterns of mammalian chordin during postgastrulation embryogenesis and in postnatal brain. Dev Dyn 217:449-456.

Shen W, Finnegan S, Lein P, Sullivan S, Slaughter M, Higgins D (2004) Bone morphogenetic proteins regulate ionotropic glutamate receptors in human retina. Eur J Neurosci 20:2031-2037.

Shi Y, Massague J (2003) Mechanisms of TGF-beta signaling from cell membrane to the nucleus. Cell 113:685-700.

Soderstrom S, Bengtsson H, Ebendal T (1996) Expression of serine/threonine kinase receptors including the bone morphogenetic factor type II receptor in the developing and adult rat brain. Cell Tissue Res 286:269-279.

Strasser GA, Rahim NA, VanderWaal KE, Gertler FB, Lanier LM (2004) Arp 2/3 is a negative regulator of growth cone translocation. Neuron 43:81-94

Sun M, Bofenkamp L, Deng CX, O’Connor MB (2006) Impairment of new environment cognition in mice with hippocampal deletion of Samd4. Soc Neurosci Abstr 32:750.756.

Varela F, Lachaux JP, Rodriguez E, Martinerie J (2001) The brainweb: phase synchronization and large-scale integration. Nat Rev Neurosci 2:229-239.

Withers GS, Higgins D, Charette M, Banker G (2000) Bone morphogenetic protein-7 enhances dendritic growth and receptivity to innervation in cultured hippocampal neurons. Eur J Neurosci 12:106-116.

Womelsdorf T, Fries P, Mitra PP, Desimone R (2006) Gamma-band synchronization in visual cortex predicts speed of change detection. Nature 439:733-736.

Xu B, Gottschalk W, Chow A, Wilson RI, Schnell E, Zang K, Wang D, Nicoll RA, Lu B, Reichardt LF (2000) The role of brain-derived neurotrophic factor receptors in the mature hippocampus: modulation of long-term potentiation through a presynaptic mechanism involving TrkB. J Neurosci 20:6888-6897.

Xu-Friedman MA, Regehr WG (2004) Structural contributions to shortterm synaptic plasticity. Physiol Rev 84:69-85.

Zakharenko SS, Patterson SL, Dragatsis I, Zeitlin SO, Siegelbaum SA, Kandel ER, Morozov A (2003) Presynaptic BDNF required for a presynaptic but not postsynaptic component of LTP at hippocampal CA1-CA3 synapses. Neuron 39:975-990.

Zhao GQ (2003) Consequences of knocking out BMP signaling in the mouse. Genesis 35:43-56.

Zhou YX, Zhao M, Li D, Shimazu K, Sakata K, Deng CX, Lu B (2003) Cerebellar deficits and hyperactivity in mice lacking Smad4. J Biol Chem 278:42313-42320. 